\title{
Hydrological Aspects of Electromagnetic Surveys
}

\author{
Baden G. Williams ${ }^{1 a}$ and John Anderson² \\ 1171 Brigalow St, Lyneham, ACT, Australia \\ ${ }^{2}$ PO Box 39, Willaura, Victoria, Australia

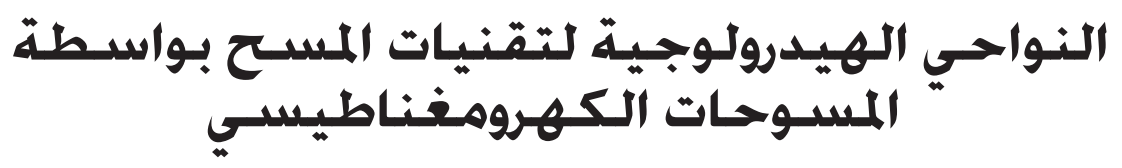 \\ بادن جـي ويليامز و جـون أندرسـون

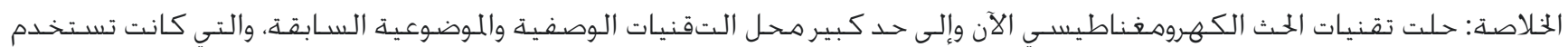

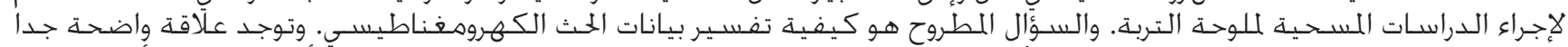

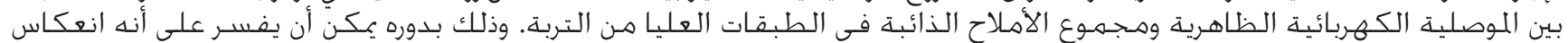

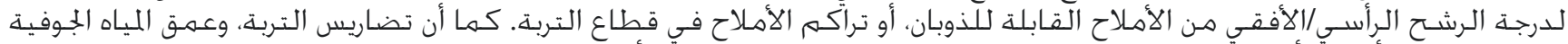

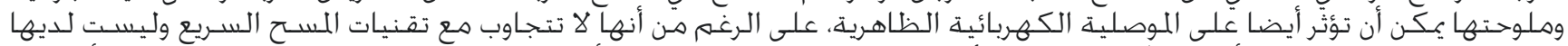

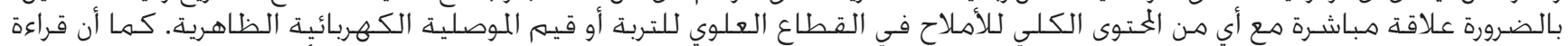

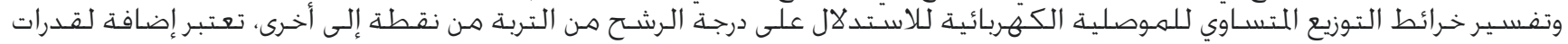

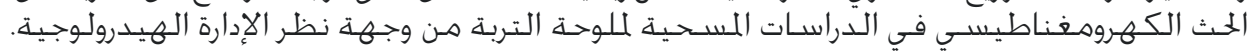 \\ كلمات مفتاحيـة: الخث الكهروهغناطيسي، تضاريس التربة، عمق المياه الجـوفية، ملوحتة المياه الجـوفيـة.
}

\begin{abstract}
Interpreting Electromagnetic (EM) surveys - Electromagnetic induction techniques have now largely replaced previous descriptive, and largely subjective, techniques used for soil salinity surveys. The question then is a matter of how to interpret the EM data. A very clear linkage exists between Apparent Electrical Conductivity (ECa) and the total soluble salts in the upper soil profile. This, in turn, can be interpreted as reflecting the degree of vertical/ lateral leaching of soluble salts, or of salt accumulation in the profile. Topography, depth to groundwater and groundwater salinity also appear to affect ECa, although they are not suited to rapid survey techniques and do not necessarily have a direct relationship with either the total salt content of the upper soil profile or the ECa values. The interpretation of isoconductivity maps in terms of the degree of leaching of the soil profile from point to point provides an added hydrological management perspective to EM soil salinity surveys.
\end{abstract}

Keywords: Salinity, electromagnetic induction (EM), topography, depth to groundwater.

\section{Introduction}

Dryland and irrigated salinity are continuing environmental and economic problems in much of Australia's farmlands. The broad mechanisms that control the severity and aerial extent of salinity are generally understood and relate to changes in the water balance of landscapes that accompany extensive land clearing, and dryland and irrigated exploitative farming practices. Although areas of secondary salinisation and groundwater systems, ranging in size from small local catchments to large regions, have been mapped for most agricultural areas in Australia (Commonwealth of Australia, 2001; Coram et al., 2000) this information is not always useful for making management decisions at a farm or paddock scale. Severely salinised areas are visually obvious to the landholder and various remedial strategies are available, but it is the areas of non-visible, potential salinisation that should also be of concern to local land managers.
Traditional soil survey and soil classification techniques resulted in a wide array of salinity types being described in the literature (Mitchell et al., 1978; Peck, 1980; SCAV, 1980; Williams and Bullock, 1989), none of which satisfied every field situation. EM induction techniques provide a more objective measure of soil salinity and since the early 1980s have largely replaced the subjective, descriptive methods. Apparent Electrical Conductivity (ECa) values, as determined by EM, have been studied in considerable detail (Rhoades and Corwin, 1981, 1989; Williams and Baker, 1982). In some instances very detailed information on salt, water and clay contents; and clay mineralogy, will be required to satisfy the objectives of a survey, whereas in other instances just the raw EM signal is all that is necessary. Obviously the larger the area being surveyed the less likely it is that every factor affecting an EM signal can be recorded. Because ECa provides a measure of the amount of leaching (vertical and 
horizontal) that has taken place in a landscape it has also been regarded as a surrogate qualitative measure of groundwater recharge/discharge (Williams, et al., 2001; Cook and Williams, 2002).

Very frequently it is the lowest parts of the landscape that are most susceptible to water logging and/or salinisation (Bettenay and Mulcahy, 1972; Malcolm, 1983) and this generalisation is often supported by electromagnetic induction (EM) survey data (Williams et al., 1990). This observation has been variously explained in terms of leaching, shallow soils, and greater depths to a groundwater body in the more elevated parts of landscapes; or alternatively, to the accumulation of fine textured soil material, shallower water tables and evaporative concentration of salts, in the lower parts. Exceptions to this generalization are also well known, particularly where hillside springs (often due to the presence of linear dykes) are present (Bennett, et al., 1995).

In order to better define the inter-relationships between EM readings and the topographic, groundwater characteristics, and soil salt content of an individual farm paddock, a single 35 ha, cropped, field was studied in detail.

\section{Experimental Design}

A detailed EM31 survey of a 750ha farm in the southwest of Victoria, Australia, has been reported previously (Williams, et al., 2006). The Geonics EM31 instrument has a transmitter to receiver coil spacing of $3.61 \mathrm{~m}$, operates at a frequency of $9.8 \mathrm{kHz}$ and has a depth of penetration of approximately $6 \mathrm{~m}$. From this survey a 35 ha field in the far south-eastern corner (P4) was chosen as representing a wide range of Apparent Electrical Conductivity (ECa) values (Fig. 1). In addition, a topographic survey of this paddock was carried out using an electronic distance meter and theodolite with readings being made at $25 \mathrm{~m}$ intervals along transects at $50 \mathrm{~m}$ spacings i.e., a similar sampling density as that used for the EM survey. Twelve recording piezometers, set at 3-hour intervals, were installed in a grid pattern that provided a good representation of the EM31 data (Fig. 2) and a tipping bucket rain gauge provided a record of all rainfall events exceeding $0.2 \mathrm{~mm}$. All elevations were reduced to a common "relative level" with the north-western corner of the paddock taken as zero.

\section{Results}

\section{EM31 Survey}

The isoconductivity map (Fig. 2) shows a wide range of ECa values with two areas of low ECa $(<60 \mathrm{mS} / \mathrm{m})$ located along the eastern boundary and a high ECa zone $(>180 \mathrm{mS} /$ $\mathrm{m})$ extending along the full length of the paddock. Two other relatively low ECa zones $(60-120 \mathrm{mS} / \mathrm{m})$ occur along the western boundary whilst another is located to the north. Despite the high ECa values there is no indication of secondary salinisation, although local knowledge indicates that this area becomes waterlogged in wet periods.

\section{Topography}

A 3-dimensional map of topography, together with the groundwater pressure surface at the time of installation, is provided in figure 3 . For purposes of clarity the vertical scale is somewhat exaggerated as there is only about $7 \mathrm{~m}$ difference between the south-east and the north-west corners. The relief is generally in the order of 2 to $3 \mathrm{~m}$ so the paddock has the appearance of being flat to very gently undulating. However there is a central drainage depression

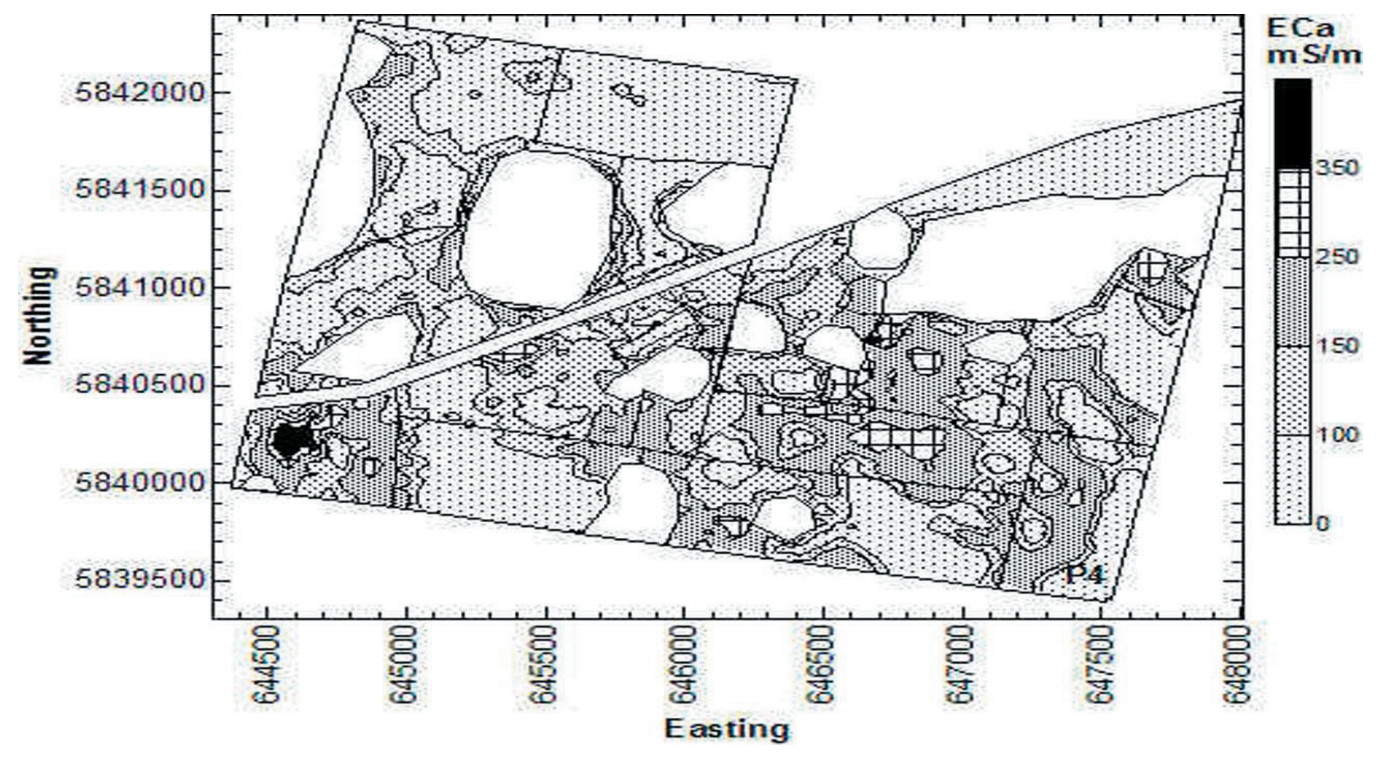

Figure 1. Whole farm EM31 survey (mS/m). Blank objects are salt lakes. 


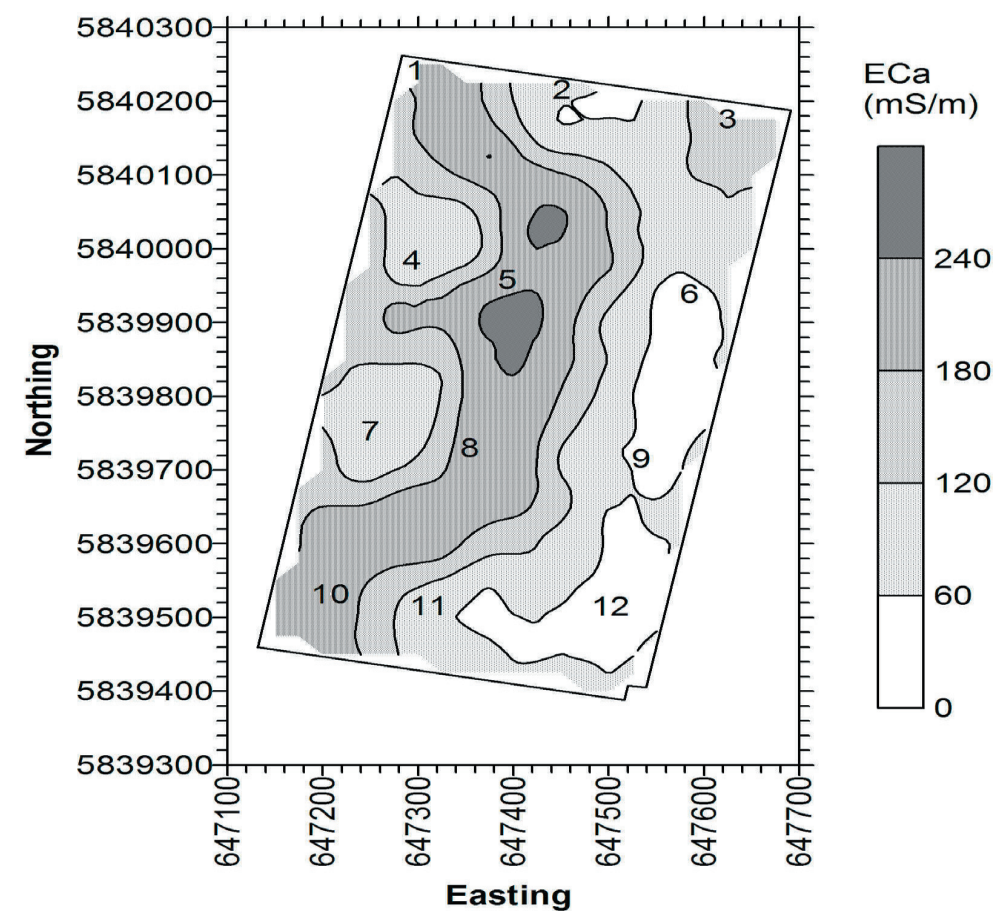

Figure 2. Isoconductivity map (mS/m) Paddock 4. Numbers are piezometer sites.

running through piezometer sites $10,8,5$ and 1 , and the landholder maintains a drain along that depression in order to more rapidly remove any excess surface water. The groundwater surface at the time of piezometer installation, although constructed from only 12 sites, appears to be relatively uniform and ranged from $+2 \mathrm{~m}$ relative elevation in the south-east to $-2 \mathrm{~m}$ in the north-west.

Superimposing the EM31 data on the topographic map shows an apparent very close relationship between ECa and elevation (Fig. 4). This perception is further enhanced

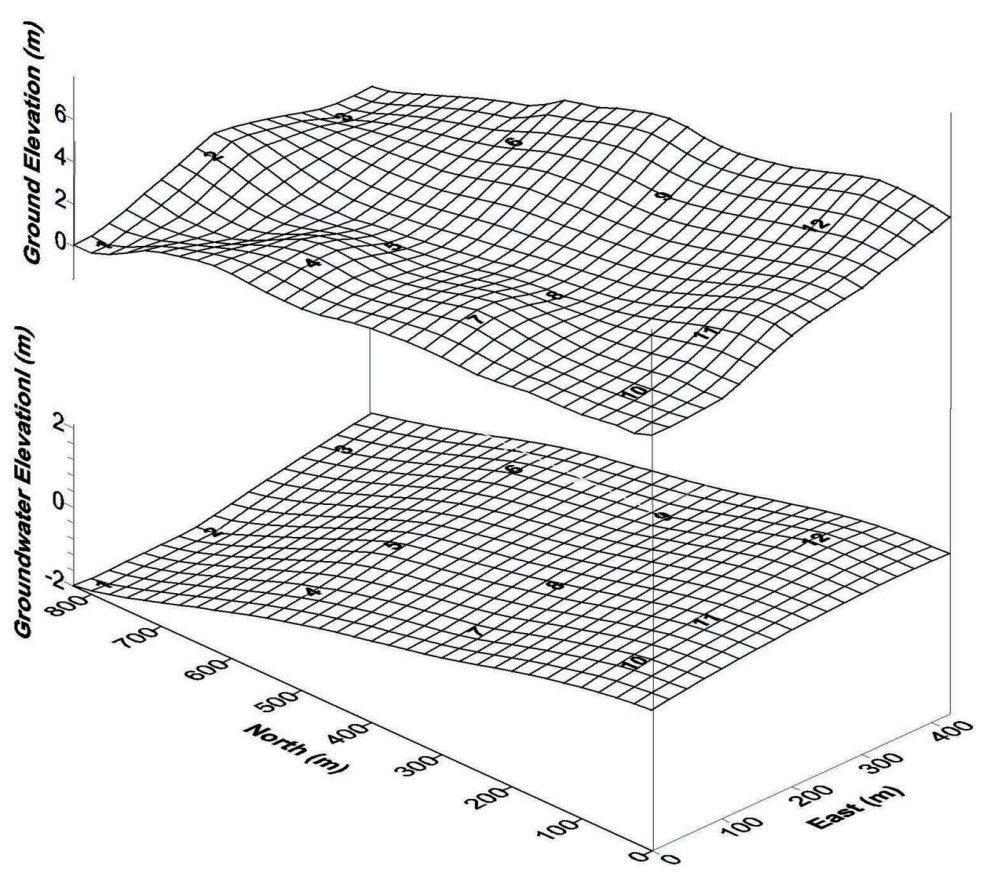

Figure 3. Combined surface and groundwater pressure surface elevations . Numbers are piezometer sites. 


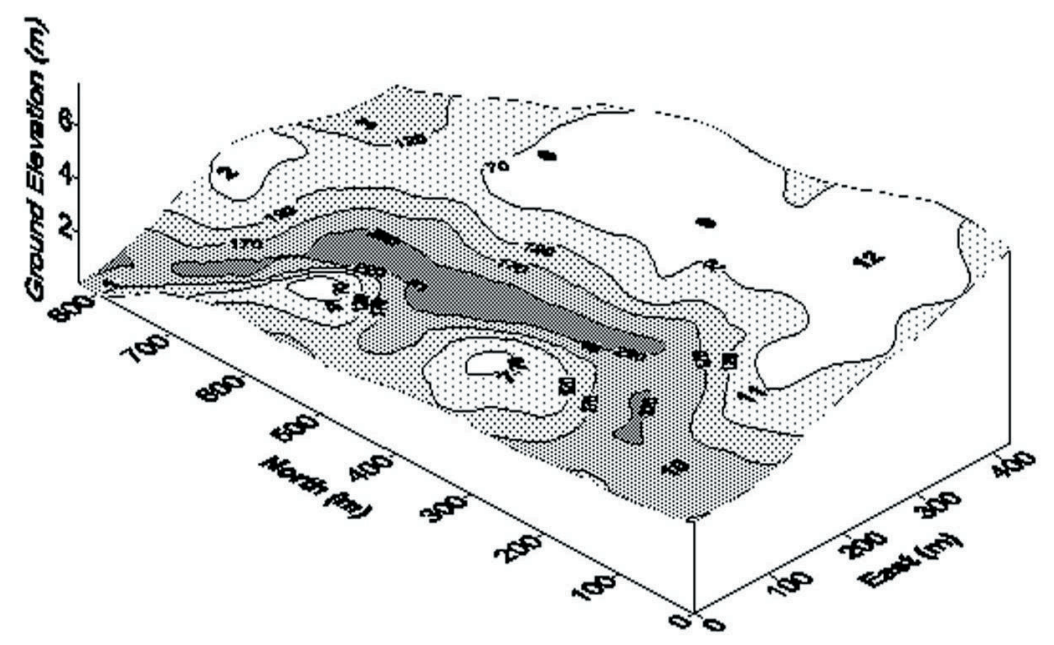

Figure 4. Isoconductivity map (mS/m) superimposed on topography.

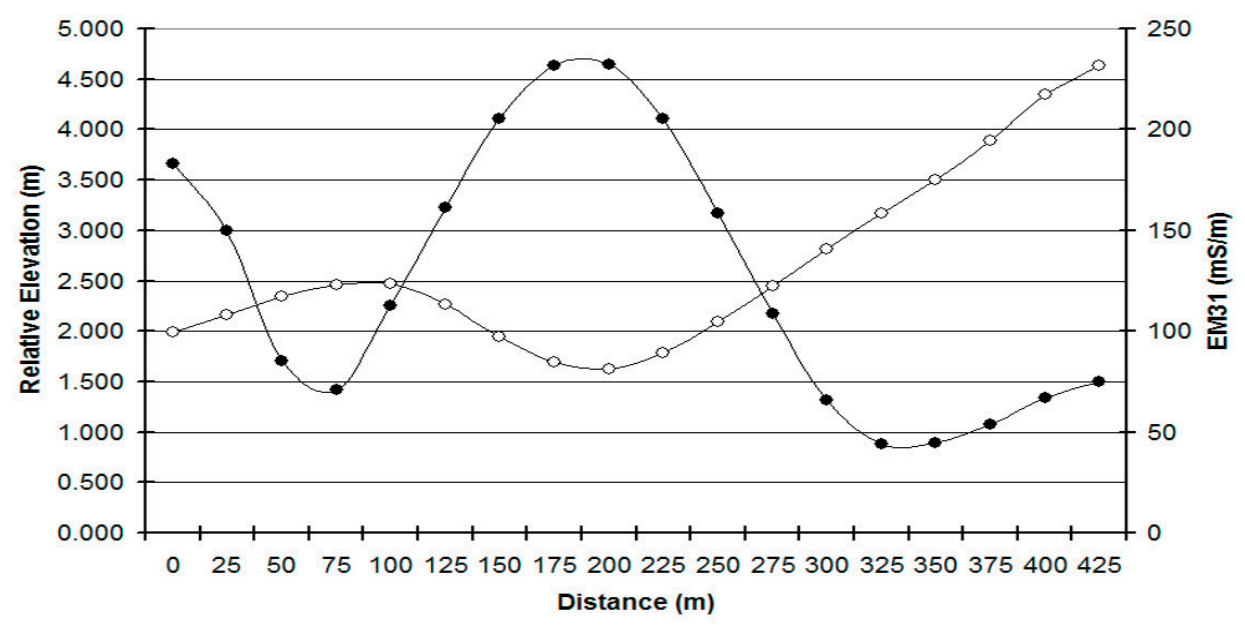

Figure 5. Soil surface - $\quad{ }^{\circ} \mathrm{ECa}$. $\quad$ CCross section through piezometers 4, 5 and 6.

by cross sections (W to $\mathrm{E}$ ) through the piezometer sites e.g., a transect through sites 4,5,6 shows a strongly inverse relationship between these two landscape parameters (Fig. $5)$. It appears that an elevation change of approximately $2 \mathrm{~m}$ can result in a change of $\mathrm{ECa}$ of $>200 \mathrm{mS} / \mathrm{m}$. However, a plot of all EM31 data against elevation (Fig. 6) shows only a very poor causal association between the two $\left(\mathrm{R}^{2}\right.$ $=0.43$ ).

This observation may be due to two separate scales of landscape elevation being present. The broader landscape is represented by the $7 \mathrm{~m}$ fall from one end of the paddock to the other, and continuing on for another fall of $4.5 \mathrm{~m}$ over the next $0.5 \mathrm{~km}$ to a large salt lake - whilst within that topographic unit there are a series of $2-3 \mathrm{~m}$ mounds and depressions superimposed on the broader landscape. These latter features will be seen to have particular importance with respect to the leaching of the soil profiles.

\section{Groundwater}

Both the salinity and the depth of the groundwater could affect the EM31 readings. Groundwater salinity was measured at the time of the piezometer installation and again, after repeated bailing, some 5 months later. The two sets of results were very similar, suggesting that recharge water from rainfall events does not mix to any great extent with the underlying groundwater body. Rather, it sits on top of the existing groundwater, where it adds to the groundwater pressure and increases lateral drainage. Although there is an apparently strong association between the groundwater salinity and ECa values (Fig. 7) $\left(\mathrm{R}^{2}=0.83\right)$ it is unlikely that there is a causal relationship because the depth to groundwater varied from $>4 \mathrm{~m}$ in the south-east corner to $<2 \mathrm{~m}$ along the central depression and, as described below, the unsaturated zones had very different salinity profiles. 


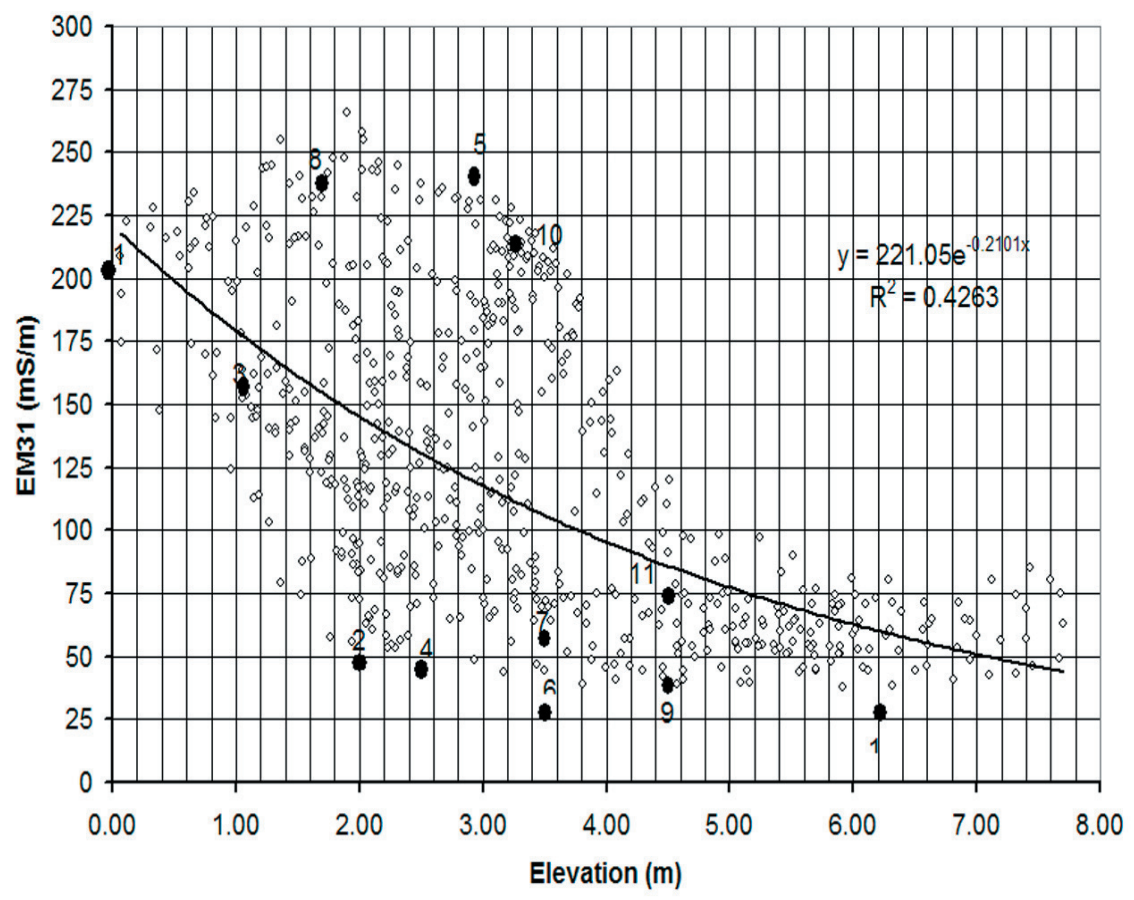

Figure 6. EM31 (mS/m) versus Elevation. Piezometer sites numbered.

Added to this, is the variable nature of the groundwater pressure surface (Fig. 8). From July 2006 the groundwater drained a further $0.5 \mathrm{~m}$ as the site experienced a period of drought. Even so, the groundwater pressure was within $2.2 \mathrm{~m}$ of the land surface along the main drainage line (site 5 ) and presumably was within capillary contact of the surface. A series of significant rainfall events from March 2007 recharged the whole landscape with the pressure surface rising by 2.5 to $3 \mathrm{~m}$. This shows quite clearly that discharge takes place along the drainage line and that it is fed by increased hydraulic pressure and lateral drainage from the adjacent more elevated areas. Thus the elevated

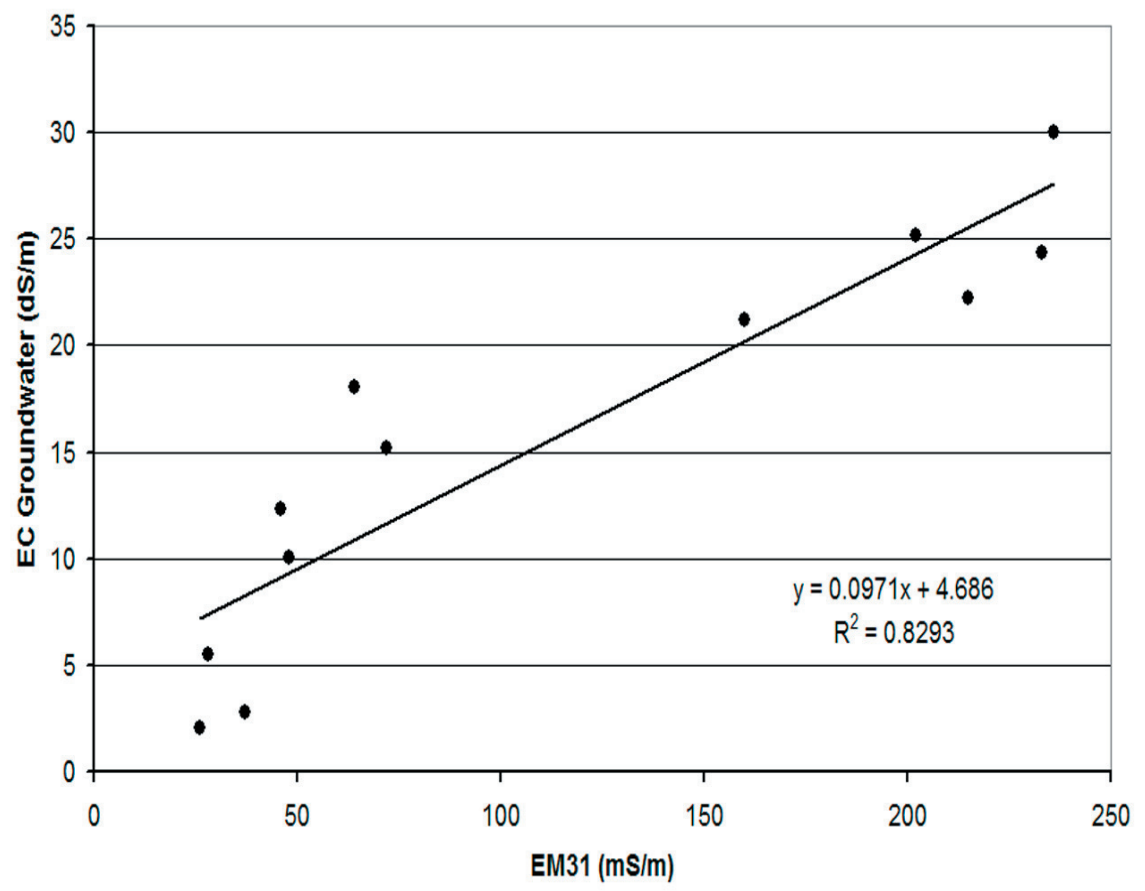

Figure 7. Groundwater salinity versus EM 31 at time of piezometer installation. 


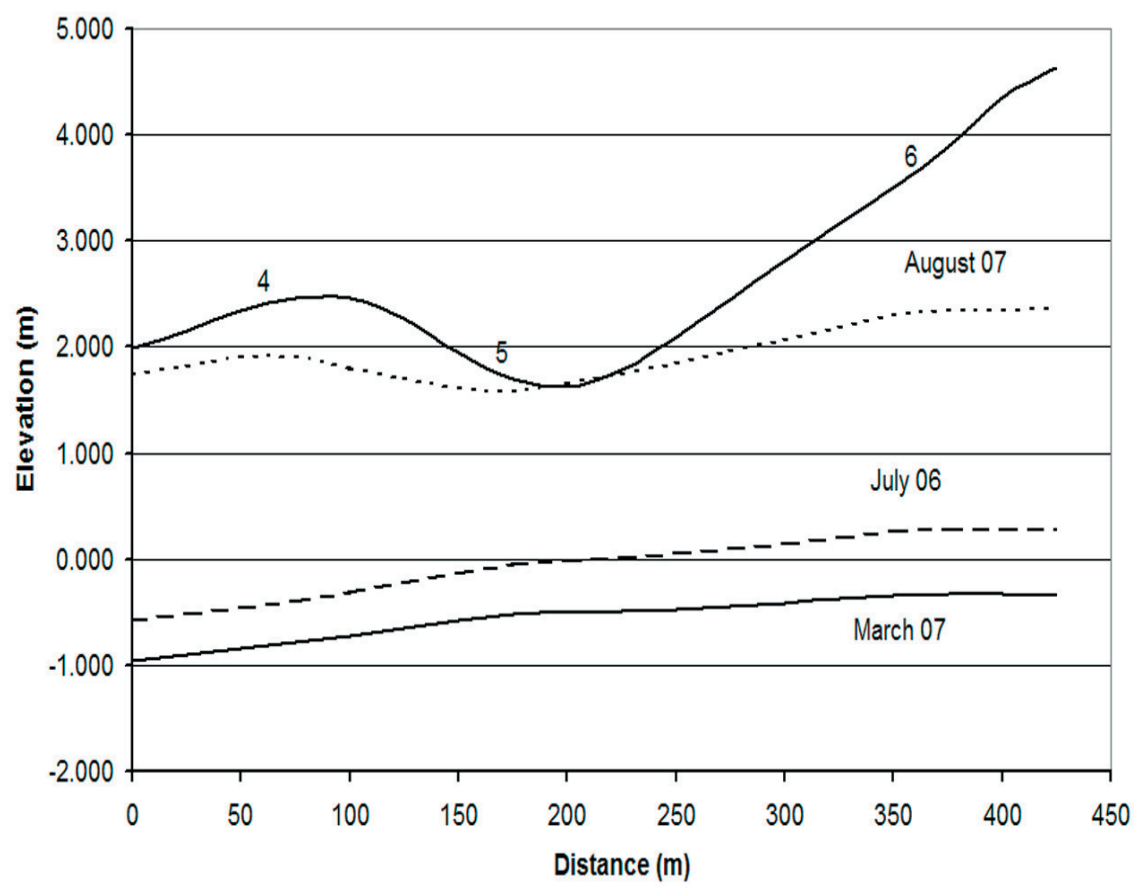

Figure 8. Groundwater pressure surfaces over time. Cross section through piezometers 4,5 and 6 .

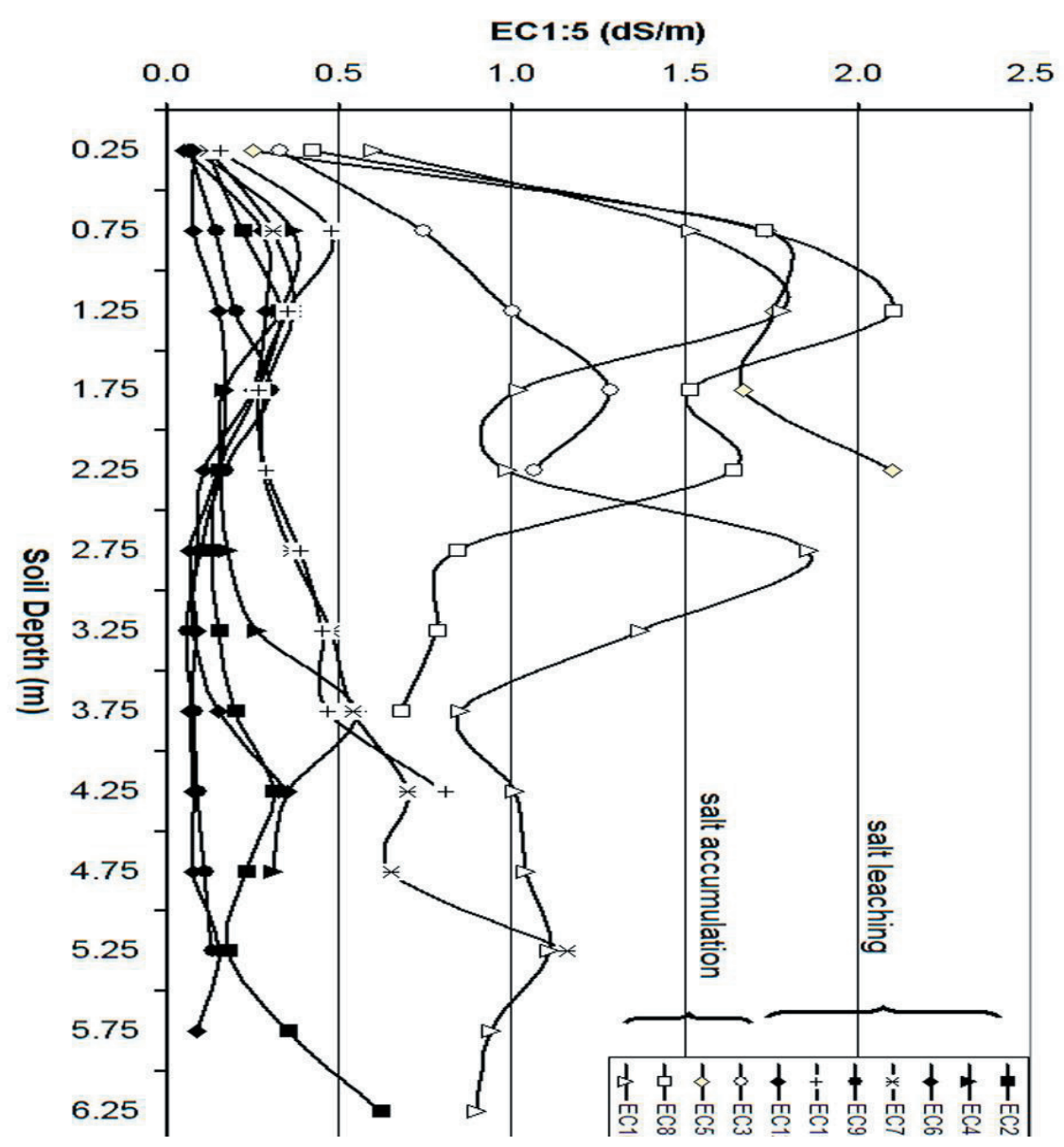

Figure 9. Soil salinity profiles at piezometer sites. 
areas are flushed of soluble salts whilst the drainage line has a net accumulation of salt due to evaporative concentration.

\section{Soil Salinity}

Figure 2 suggests that sites 1,5,8 and 10, with the highest ECa values, represent areas susceptible to salt accumulation, whereas the remainder have been leached of soluble salt to various degrees. This is confirmed in figure 9 where the EC of 1:5 soil:water extracts are shown against depth in the profile. Site 1 soil samples were lost whilst sites 3 and 5 could not be sampled below a depth of $2.5 \mathrm{~m}$ due to the shallow water table at the time of piezometer installation. The area under each $\mathrm{EC}_{1: 5}$ profile (i.e., depth * electrical conductivity) can be regarded as a measure of the total soluble salt content of the profile. Relating this to the EM31 readings to a depth of $2.5 \mathrm{~m}$ yields;

Total Soluble Salt $=0.016 *$ EM31 $-0.2177 \quad R^{2}=0.985$

$(\mathrm{mS} / \mathrm{m})$

The salinity profiles can be clearly divided into those where salt is being leached downwards and those where salt is accumulating. All profiles showed a bulge of soluble salt at a depth of 1.5 to $2 \mathrm{~m}$ where a layer of carbonate has accumulated. This appears to be aeolian in nature (i.e., blown out of nearby salt lakes) but some could also be due to more modern carbonate precipitation in those areas where the water table is shallowest. Site 10 had a further complication due to a near surface accumulation of maghaemite gravel that had been washed down from ranges to the south. The EM31 signal is responsive to this material and the electrical conductivity of 1:5 suspensions is also higher when this magnetic material is present (Williams and Fidler, 1983).

\section{Discussion}

The total salt content within the upper soil profile $(<6 \mathrm{~m})$ has been shown to have a strong correlation with Apparent Electrical Conductivity (E a) as measured with an EM31 electromagnetic conductivity meter. Thus, various parts of landscapes can be classified by their tendency to 'leach' or 'accumulate' soluble salts, regardless of the absolute salinity status; i.e., the technique is not site specific nor are the absolute values of ECa of prime importance with respect to water movement within the soil profiles. It is the relative change of ECa from point to point that provides information on water movement, both horizontally and vertically, within the landscape.

An old truism states that "recharge (and hence leaching of soluble salts) occurs over all parts of a landscape unless they are actively discharging". Thus in the absence of any topographic or hydrological information, figure 2 could be interpreted in terms of the degree to which various parts of the paddock have been leached, or have accumulated soluble salts.

This immediately adds a hydrological aspect to the initial EM survey. One can infer that recharge water in the vicinity of sites 6,9 and 12 either flows laterally towards the central high ECa area (sites 1, 5, 8 and 10), and/or increases the hydraulic gradient between the former and the latter sites. Although sites 1,5,8 and 10 are obviously accumulating soluble salt in the upper part of the profile (presumably by evaporative concentration) it does not mean that those sites do not also experience recharge - at least up until the stage when discharge to the land surface commences. Thus the whole landscape/ recharge interaction is not a static function, but rather the isoconductivity map provides a good picture of the resultant of the recharge and groundwater dynamics. This then provides a more realistic appraisal of the actual and potential for secondary salinisation.

This argument then has important implications for land management practices. Just because an area can be defined as having a low soluble salt content does not mean that it can be ignored when attempting to manage secondary salinisation. In fact such areas play a major role in raising the groundwater pressure surface in adjacent land, and hence increasing the potential for salt accumulation in those other areas. From figure 2 it would appear prudent, in this case, to intercept rainfall in the areas defined as having ECa values of $<60 \mathrm{mS} / \mathrm{m}$, and possibly extending that to $<120 \mathrm{mS} / \mathrm{m}$. An agroforestry solution would seem to be a suitable land use, but a perennial pasture or pasture-cropping would also have the desired hydrological/ salinity outcomes.

Soil water content will also affect absolute EM values in the sense that a wet profile is more electrically conductive than a dry profile. But, the relative pattern obtained in a surveyed area will remain very much the same - regardless of the weather conditions (Cook and Williams, 2002). This aspect is particularly important in the choice of the EM instrument used. For the Geonics series (EM38, EM31, EM34/3) the EM31, with an effective depth of penetration of about $6 \mathrm{~m}$, has the advantage of being less sensitive to surface soil moisture content than the shallower sounding EM38, and is much easier to use than the $10 \mathrm{~m}$ spacing of the EM34/3. However, the final choice will depend largely on the operators' preferences - all will provide a very accurate map of the relative change in ECa from point to point within a survey area. This, in turn, provides an accurate map of the tendency for leaching from point to point, and helps to define those areas most in need of recharge control measures.

\section{Conclusion}

EM surveys provide a good guide not only to areas of immediate risk of salinisation but also to areas of potential secondary salinisation. This assessment can then be further improved by interpreting the isoconductivity map in terms of the degree to which salts are leached from, or accumulate in, various parts of the landscape i.e., the pattern of vertical and horizontal water movement.

Very low ECa areas, whilst not presenting a salinity problem, might well be the source areas of water that creates 
discharge, and possibly salt accumulation, in other parts of the landscape. Such information should be of considerable value to land managers when determining what strategies would be suitable for managing soil salinity.

\section{References}

Bennett, D.L., R.J. George, and B.Whitfield. 1995. The use of ground EM systems to accurately assess salt store and help define land management options for salinity management. Exploration Geophysics 31:249-245.

Bettenay, E. and M.J. Mulcahy. 1972. Soil and landscape studies in Western Australia. 2. Valley form and surface features in the south-west drainage division. Journal of Geological Society of Australia 18:359-369.

Commonwealth of Australia. 2001. National Land and Water Resources Audit: Australian Dryland Salinity Assessment 2000.

Cook, P.G. and B.G. Williams. 2002. The basics of recharge and discharge. Part 8. Electromagnetic induction techniques. Lu Zhang and Glen Walker (Editors). CSIRO Publishing.

Coram, J.E., P.R. Dyson, P.H. Houlder, and W.R. Evans. 2000. Australian Groundwater Flow Systems contributing to Dryland Salinity. A report prepared for the National land and water resources Audit Dryland Salinity Theme. Bureau of Rural Sciences, Canberra, A.C.T.

Malcolm, C.V. 1983. Wheatland salinity. Western Australia Dept Agric. Tech. Bull. No.52.

Mitchell, A., S. Zallar, J.J. Jenkin, and F.R. Giggons. 1978. Dryland salting in Victoria, Australia. In: Dryland Saline Seep Control Proc. Meeting of the SubCommission on Salt Affected Soils at the 11th Int. Soil Sci. Congr., Edmonton, Alberta, Canada.

Peck, A.J. 1980. Causes and treatment of secondary salinity. In: Salinity and Water Quality, A.J. Rixon and R.J. Smith (Editors), Proceedings Symposium, Darling Downs Inst. Adv. Ed., Toowoomba, Queensland, Australia.
Rhoades, J.D. and D.L. Corwin. 1981. Determining soil electrical conductivity - depth relations using an inductive electromagnetic soil conductivity meter. Soil Science Society of America Journal 45:255-260.

Rhoades, J.D. and D.L. Corwin. 1989. Soil electrical conductivity: effects of soil properties and application to soil salinity appraisal. Resource Monitoring Workshop, Vitorian Department of Agriculture and Rural Affairs, Mooroopna, Victoria, Australia.

SCAV (Soil Conservation Authority of Victoria). 1980. Salting of non-irrigated lands in Australia. SCAV, Australia. Govt. Printer: Melbourne.

Williams, B.G. and G.C. Baker, 1982. An electromagnetic induction technique for reconaissance surveys of soil salinity hazards. Australian Journal of Soil Research 20:107-118.

Williams, B.G. and F-T. Fidler. 1983. The use of electromagnetic induction for locating subsurface saline material. In: Relation of Groundwater Quantity and Quality, Proceedings of Hamburg Symposium, IAHS Pub. No. 146.

Williams, B.G. and P.R. Bullock. 1989. The classification of salt-affected land in Australia. Commonwealth Scientific and Industrial Research Organization (CSIRO), Division of Water Resources, Tech.Memo. $89 / 8$.

Williams, B.G., D.P. Richardson, and J. Walker. 1990. Spatial variability of apparent electrical conductivity. CSIRO Division, Water Resources Technology, Memo. 90/6.

Williams, B.G., J. Walker, and H. Tane. 2001. Drier landscapes and rising watertables. Natural Resource Management 4:10-18.

Williams, B.G., J. Walker, and J. Anderson. 2006. Spatial variability of regolith leaching and salinity in relation to whole farm planning. Australian Journal of Experimental Agriculture 46:1271-1277.

Received: April 4, 2010

Accepted: January 22, 2013 